\title{
PID controller using rapid control prototyping techniques
}

\author{
Odair A. Trujillo ${ }^{1}$, Nicolás Toro-García ${ }^{2}$, Fredy E. Hoyos ${ }^{3}$ \\ 1,2Department of Electrical and Electronics Engineering \& Computer Sciences, Universidad Nacional de Colombia - Sede \\ Manizales, Colombia \\ ${ }^{3}$ Universidad Nacional de Colombia - Sede Medellín - Facultad de Ciencias - Escuela de Física, Colombia
}

\begin{tabular}{ll} 
Article Info & ABSTRACT \\
\cline { 3 - 3 } Article history: & $\begin{array}{l}\text { To analyze the performance of the PID controller in a buck type converter } \\
\text { implemented in real time. We begin by designing a continuous controller using } \\
\text { the analytical method for calculating PIDs. Pulse width modulation is then }\end{array}$ \\
$\begin{array}{l}\text { Received Jun 19, } 2018 \\
\text { Asevised Dec 18, } 2018\end{array}$ & $\begin{array}{l}\text { und bed and bifution diagrams analyzed to reveal some problems of switching } \\
\text { and sampling time. The model converter is then implemented with a PID } \\
\text { controller in dSPACE. The experimental results provide detailed requirements } \\
\text { of sampling frequency and switching speed, and show the performance of the }\end{array}$ \\
\hline Keywords: & $\begin{array}{l}\text { PID controller. Converters are used in power generation solar systems and } \\
\text { conmuted power sources for feed telecommunication devices, smart grids, and } \\
\text { other applications. }\end{array}$ \\
DC-DC converters &
\end{tabular}
analysis

Numerical bifurcation

PID hardware

PID software

Rapid control prototyping

Copyright $\left({ }_{0} 2019\right.$ Institute of Advanced Engineering and Science. All rights reserved.

\section{Corresponding Author:}

Fredy E. Hoyos,

Facultad de Ciencias - Escuela de Física,

Universidad Nacional de Colombia - Sede Medellín,

Carrera 65 Nro. 59A-110, Medellín, Colombia.

Email: fehoyosve@unal.edu.co

\section{INTRODUCTION}

The buck converter is a switching power supply with two semiconductor devices [1], a transistor $(Q)$ and diode $(D)$, an inductor $(L)$, an output capacitor $(C)$, and its respective load as shown in Figure 1 . This system converts an unregulated DC voltage to another regulated lower voltage. The transistor switches the input power $E$ by pulse width modulation (PWM) to feed the filter $L C$. The diode conducts when the transistor is off if there is positive current in the coil. The inductor does not allow rapid changes in current and the capacitor does not support abrupt changes of voltage, creating between them a low pass filter. A MOSFET is used for switching, thus, the control technique must determine the OFF and ON switch times. This control form is known as pulse width modulation (PWM) [2]-[6].

Figure 2 shows a block diagram of the system under study. This system is divided into two major subgroups: the hardware that includes the physical and electronic components and the software implemented on a dSPACE, which performs the signal acquisition and implementation of PID control technique. The hardware consists of a sensors (high-impedance resistors connected in parallel) to measure the $V_{C}$ state variable (capacitor voltage). The converter's switch is handled from the control and development card through the PWM and the pulse is opto-isolated through fast optocouplers. The digital part is developed in the control and development card dSPACE DS1104 [7], where the PID control technique is implemented. PID was used due to its easy availability and compatibility with some series of PLCs, DCS software, Advantech 6022, and popular software such as LabView and MATLAB [8], [9]. The card is programmed using the MATLAB/Simulink@ platform and has a display interface called "ControlDesk." The controller is implemented in Simulink $囚$ and downloaded to the DSP to operate at a given frequency [10]. The state variable 
comes to the controller through the 12-bit ADC input with a sampling rate set for the experiment at $10 \mathrm{kHz}$ and then $30 \mathrm{kHz}$. The controller parameters are set through variable gain blocks because they were tuned in real time. At each sampling period, the controller calculates the duty cycle in real time and its equivalent in the PWM control switch.

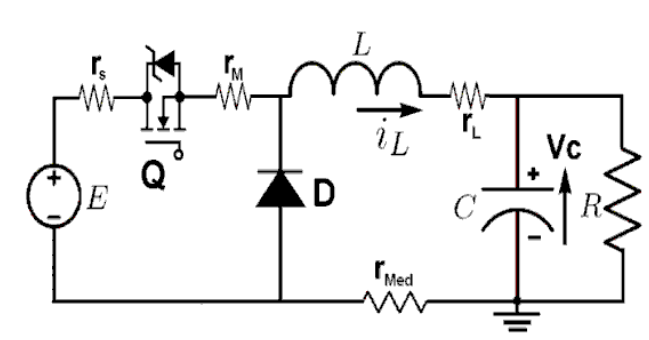

Figure 1. Schematic of buck converter model

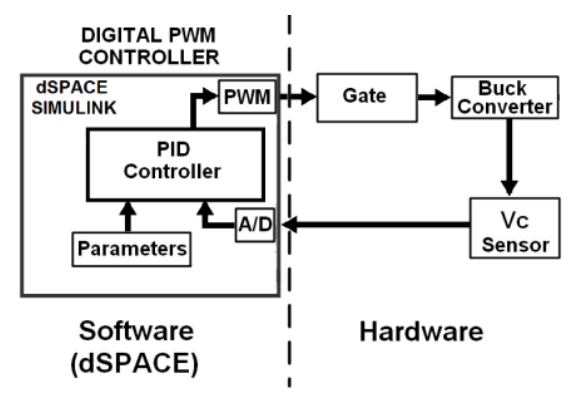

Figure 2. Block diagram of the proposed system

This article is intended for the digital PWM approach, which presents rich nonlinear dynamics and has the following advantages: immunity to analog component variations; faster process design; low sensitivity to changes in parameters; programmability; allows reduction or elimination of passive external components; allows calibration of protection algorithms; and supports digital system interfaces for implementing nonlinear control techniques [11]-[16]. However, the DPWM also has disadvantages as it is affected by two limitations: quantization effects [12], [13] and delays in the control loop [17], [18].

\section{BUCK CONVERTER MODEL}

$$
E=\left(r_{\mathrm{int}}+r_{L}\right) i_{L}+L i_{L}+V_{C}
$$

Where $r_{\text {int }}$ is the internal resistance of the MOSFET $\left(r_{M}\right)$ plus the resistance source $\left(r_{S}\right)$ and the resistance coil $\left(r_{L}\right)$ plus the shunt resistor's resistance used for the current measure $\left(r_{\text {Med }}\right)$ as shown in Figure 1. By summation of currents in the capacitor's node we obtain

$$
C V_{C}=i_{L}-\frac{V_{C}}{R}
$$

Solving and simplifying gives

$$
\begin{aligned}
& i_{L}=-\frac{r_{\text {in }}+r_{L}}{L} i_{L}-\frac{1}{L} V_{C}+\frac{E}{L}, \\
& V_{C}=\frac{1}{C} i_{L}-\frac{1}{R C} V_{C} .
\end{aligned}
$$

Converting to matrix form gives

$$
\begin{aligned}
& {\left[\begin{array}{l}
i_{L} \\
V_{C}
\end{array}\right]=\left[\begin{array}{cc}
-\frac{r_{\text {int }}+r_{L}}{L} & -\frac{1}{L} \\
\frac{1}{C} & -\frac{1}{R C}
\end{array}\right]\left[\begin{array}{l}
i_{L} \\
V_{C}
\end{array}\right]+\left[\begin{array}{l}
E \\
L \\
0
\end{array}\right],} \\
& y=\left[\begin{array}{ll}
0 & 1
\end{array}\right]\left[\begin{array}{c}
i_{L} \\
V_{C}
\end{array}\right] .
\end{aligned}
$$


Converting to state variables and making $a=\frac{r_{\text {int }}+r_{L}}{L}, b=\frac{1}{L}, c=\frac{1}{C}, d=\frac{1}{R C}$, and maintaining signs gives

$$
\begin{aligned}
{\left[\begin{array}{l}
X_{1} \\
X_{2}
\end{array}\right] } & =\left[\begin{array}{cc}
-a & -b \\
c & -d
\end{array}\right]\left[\begin{array}{l}
X_{1} \\
X_{2}
\end{array}\right]+\left[\begin{array}{l}
E \\
L \\
0
\end{array}\right], \\
y & =\left[\begin{array}{ll}
0 & 1
\end{array}\right]\left[\begin{array}{l}
X_{1} \\
X_{2}
\end{array}\right] .
\end{aligned}
$$

If the switch stays $\mathrm{OFF}(\mathrm{u}=0)$, then the equation becomes $\mathrm{X}=\mathrm{AX}$ because it does not take into account the diode's voltage.

In the case where the switch is closed, we find the transfer function using

$$
G(s)=\frac{Y(s)}{U(s)}=C(S I-A)^{-1} B
$$

which yields

$$
G(s)=\frac{\frac{c}{L} E}{s^{2}+(a+d) s+(a d+b c)} .
$$

In (2), the following values will be replaced to find the system's response:

$$
\begin{gathered}
E=40 \mathrm{~V}, C=46.27 \mu F \\
R=39.3 \Omega, r_{\text {int }}=0.688 \Omega \\
L=2.47 \mathrm{mH}, r_{L}=1.345 \Omega
\end{gathered}
$$

$$
G(s)=\frac{8.739606}{s^{2}+1372 s+9.192806}
$$

The poles for (3) are

$$
-681 \pm j 2953 \text {. }
$$

The root locus is shown Figure 3. Therefore, the system is stable with the values used for constants and it is underdamped. The response to stepped $E$ volts can be seen in Figure 4, which shows an overshoot that must be reduced and a steady-state error of about 2 volts, indicating the system is underdamped. In low-power buck converters, such as computer sources, it is usual to find a zener diode and transistor-based regulation of the converter output. This technique has the advantage of avoiding the use of control; however, it has the disadvantage of increasing the probability of failure on points where it handles the power output. To obtain the desired voltage with proper MOSFET handling and without adding elements that may fail in the converter output is the goal of implementing a controller.

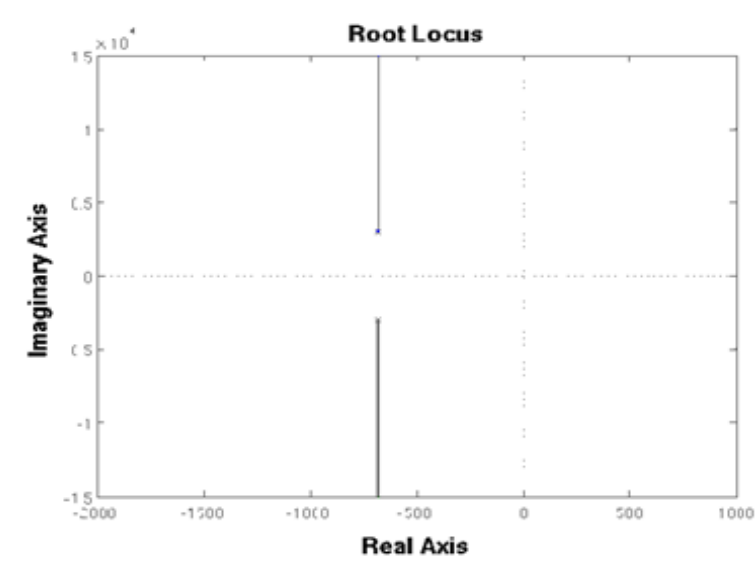

Figure 3. Root locus

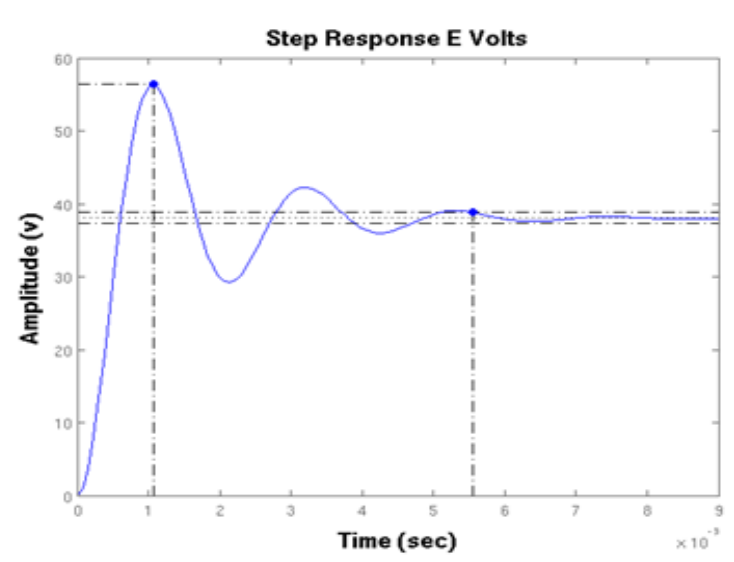

Figure 4. Step response 


\section{CONTINUOUS PID CONTROLLER}

The method used is known as the "analytical method." We start from the desired behavior as determined by the second-order canonical equation, which should match the characteristic equation of the closed-loop system with PID, to find the constants $K p, K d$, and $K i$.

\subsection{Desired response}

$$
t s=2.5 \mathrm{~ms}, \mathrm{Mp}=10 \%=0.1
$$

$$
\begin{gathered}
\zeta=\sqrt{\frac{\ln (M p)^{2}}{\pi^{2}+\ln (M p)^{2}}}=\sqrt{\frac{\ln (0.1)^{2}}{\pi^{2}+\ln (0.1)^{2}}}=0.591 \\
\sigma=\frac{4}{t s}=\frac{4}{2.5 m s}=1600 \\
\sigma=\zeta . \omega_{n} \Rightarrow \omega_{n}=\frac{1600}{0.591}=2707.27
\end{gathered}
$$

Second-order canonical equation (desired behavior):

$$
\begin{aligned}
& \frac{\omega_{n}^{2}}{s^{2}+2 \cdot \zeta \cdot \omega_{n}+\omega_{n}^{2}} \\
& \frac{2707^{2}}{s^{2}+3200 s+2707^{2}}
\end{aligned}
$$

Poles on:

$$
-1.600 \pm j 2.183
$$

\subsection{Closed loop with unknown PID constants}

Replacing the parameters in the transfer function and making a change of variables $m=8739229$, $n=1372$, and $p=9191377$, we must close the loop with unknown PID. Block diagram as shown in Figure 5.

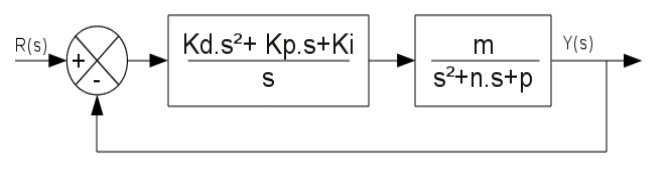

Figure 5. Block diagram

This gives the transfer function with the unknown constants of PID:

$$
G l c(s)=\frac{m K d s^{2}+m K p s+m K i}{s^{3}+(n+m K d) s^{2}+(p+m K p) s+m K i^{*}}
$$

However, before matching the characteristic equations, we must first increase the degree of the second-order characteristic equation. This is achieved by adding a remnant pole to the characteristic equation so as to not affect the desired behavior; in this case, that is five times away from the dominant poles. This modification usually affects the amplitude, but the behavior of the canonical system is preserved:

$$
(s+8000)\left(s^{2}+3200 s+2707^{2}\right) \text {. }
$$

Thus, it is now possible to match the coefficients:

$$
\begin{aligned}
& (n+m K d)=11200 \Rightarrow K d=0.0011245, \\
& (p+m K p)=32929310 \Rightarrow K p=2.7162, \\
& (m K i=5)=863448 e 10 \Rightarrow K i=6709 .
\end{aligned}
$$


Replacing these constants in the closed-loop transfer function, the simulation is then performed with a step value of $E$ volts.

Figure 6 shows that the controlled system does not reach the desired overshoot; however, it is normal to do some tuning, preferably when the controller is already modulated by the PWM so as to avoid double tuning. The settling time and the steady-state error are the desired outcomes.

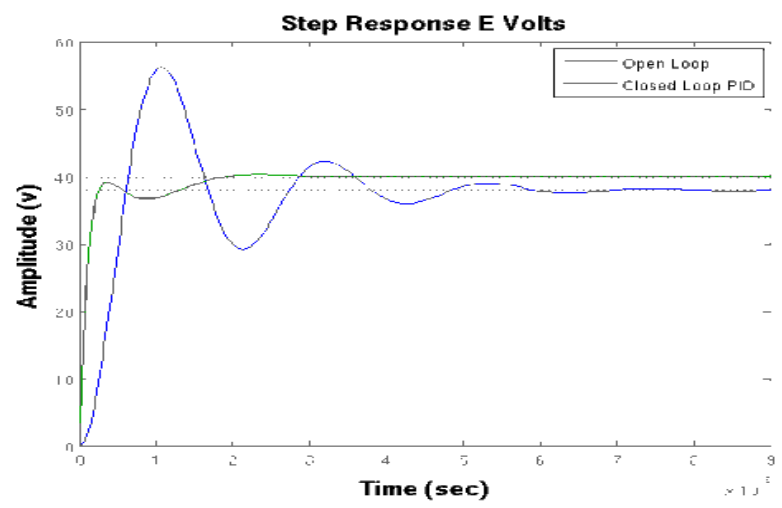

Figure 6. Comparison of step response in open-and closed-loop systems with PID

\section{DISCRETE TIME SYSTEM}

For a continuous time, system, the general solution is given by

$$
X(t)=e^{A\left(t-t_{o}\right)} X(0)+\int_{t_{o}}^{t} e^{A(t-\tau)} B u(\tau) \mathrm{d} \tau .
$$

Therefore, the solution in discrete time form is given by

$$
X(k+1) T=e^{A T} X(k T)+\int_{0}^{T} e^{A(T-\tau)} B u(k T) \mathrm{d} \tau .
$$

The solution of Equation (4) is obtained as

$$
X(k+1) T=e^{A T} X(k T)+\left(e^{A T}-I\right) A^{-1} B u(k T) .
$$

Making $A d=e^{A T}$ y $B d=\left(e^{A T}-I\right) A^{-1} B$, the solution can be presented as

$$
A d \cdot X(k T)+B d \cdot u(k T)
$$

Then, the solution of $e^{A T}$ is

$$
C^{-1}(S I-A)^{-1}=\left(\begin{array}{cc}
\frac{s+a}{s^{2}+(a+d) s+(a d+b c)} & -\frac{a}{s^{2}+(a+d) s+(a d+b c)} \\
\frac{c}{s^{2}+(a+d) s+(a d+b c)} & \frac{s+a}{s^{2}+(a+d) s+(a d+b c)}
\end{array}\right)
$$

From (6) and applying Laplace's anti-transformation, we obtain the matrix $e^{A T}$ :

$$
e^{A T}=\left(\begin{array}{cc}
\text { Term } 2+d T e r m 1 & -b T e r m 1 \\
c T e r m 1 & \text { Term } 2+\text { aTerm } 1
\end{array}\right)
$$

where

$$
\begin{array}{ll}
\operatorname{Term} 1=\frac{e^{-\zeta \omega_{n} t} \operatorname{sen}\left(\omega_{d} t\right)}{\omega_{d}} & , \operatorname{Term} 2=-\frac{e^{-\zeta \omega_{n} t} \operatorname{sen}\left(\omega_{d} t\right)-\phi}{\sqrt{1-\zeta^{2}}}, \\
\text { and } & \\
\omega_{d}=\omega_{n} \sqrt{1-\zeta^{2}} ; \quad \phi=\tan ^{-1} \frac{\sqrt{1-\zeta^{2}}}{\zeta} .
\end{array}
$$

At this point, we probe that $e^{A T}$ evaluated at $t=0$ is equal to the identity matrix. 
Knowing $e^{A T}$, an algorithm was implemented in MATLAB $₫$ to produce the discrete equivalent shown in Figure 7. The continuous time system has $T s=5.9 \mathrm{~ms}$, so we can choose a sampling rate $T=50 \mu$ seg. Initializing the necessary variables, we obtain the output shown in Figure 7. Thus, we can see how the discrete equivalent is very close to the real equivalent.

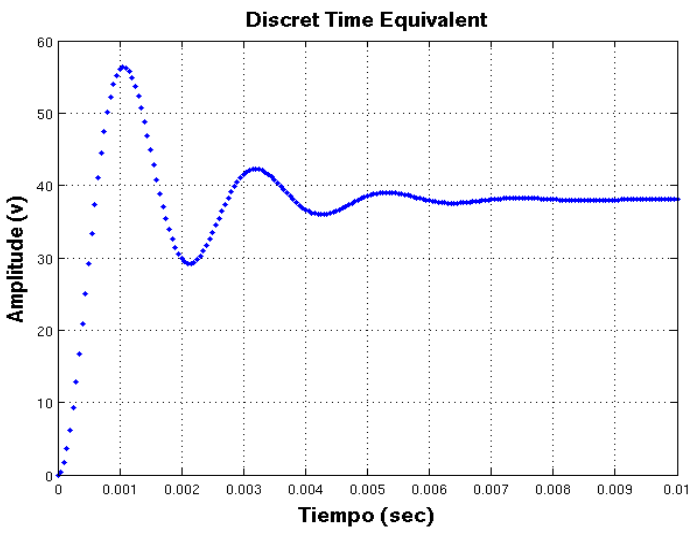

Figure 7. Discrete time equivalent

\section{PID MODULATED BY PWM}

The found constants will be used in this controller. Initializing variables and respective vectors to zero the output $\left(V_{C}\right)$ (load voltage) shown in Figure 8. We observe that the overshoot appears even higher than previously estimated; to reduce the overshoot, we follow Table 1 taken from [13], showing an online tuning form of PID, depending on the output characteristics required by the user. This table is valid as long as the constants to tune are calculated with a known method. Therefore, from the values that we have calculated, we reduce $K i=2400$ to obtain an overshoot close to zero as shown in Figure 9, which is very convenient for such converters.

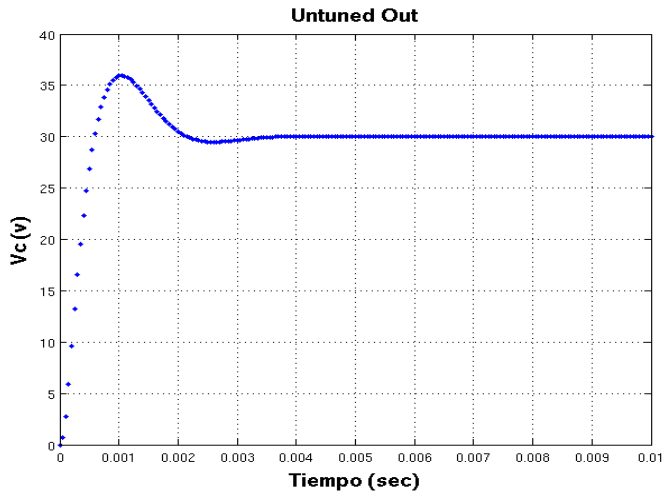

Figure 8. PID with PWM

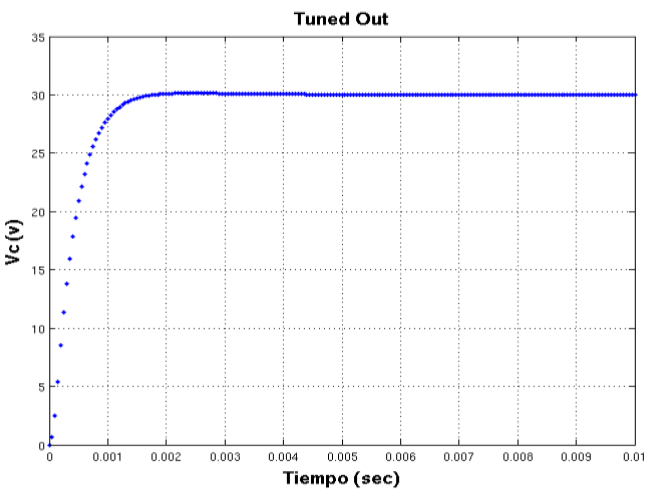

Figure 9. Tuned output $\left(V_{C}\right)$ using Table 1

Table 1. Effects of Independent $P, I$, and $D$ Tuning

\begin{tabular}{cccccc}
\hline PID & Rise Time & Overshoot & Settling Time & Steady Stage Error & Stability \\
\hline$\Uparrow K p$ & Decrease & Increase & Small increase & Decrease & Degrade \\
$\Uparrow K \mathrm{i}$ & Small decrease & Increase & Increase & Large decrease & Degrade \\
$\Uparrow K d$ & Small decrease & Decrease & Decrease & Minor change & Improve \\
\hline
\end{tabular}

\section{BIFURCATION DIAGRAMS}

Bifurcation diagrams are defined as qualitative and quantitative variations of the system's dynamics in front of the variation of parameters that can influence the stability of the system and characteristics of the output, among other issues. 
The bifurcation diagram is a tool to analyze the dynamic system and provides information on it limits of stable operation. For this system, only the constant $K p$ has to be varied as this affects the others.

This requires the industrial form of PID:

$$
P I D=k p\left(1+\frac{\tau_{i}}{s}+\tau_{d} s\right)
$$

\subsection{Vcand $D$ bifurcation diagrams with Kp variations}

Figures 10 and 11 show that the operating range of $K p$ has an upper limit of 19 units apx before the system becomes chaotic.

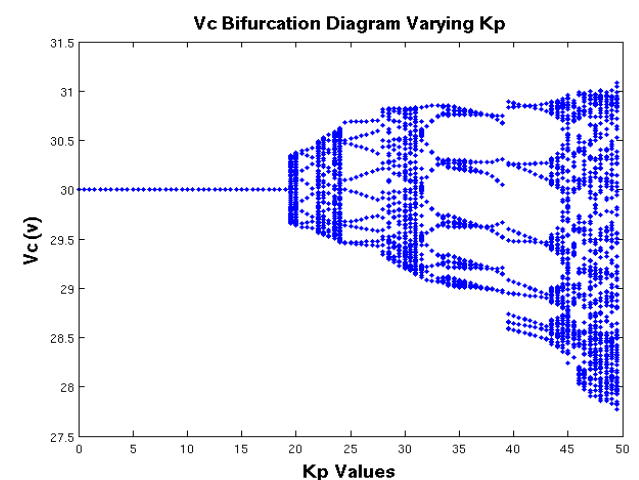

Figure 10. $V_{C}$ 's bifurcations

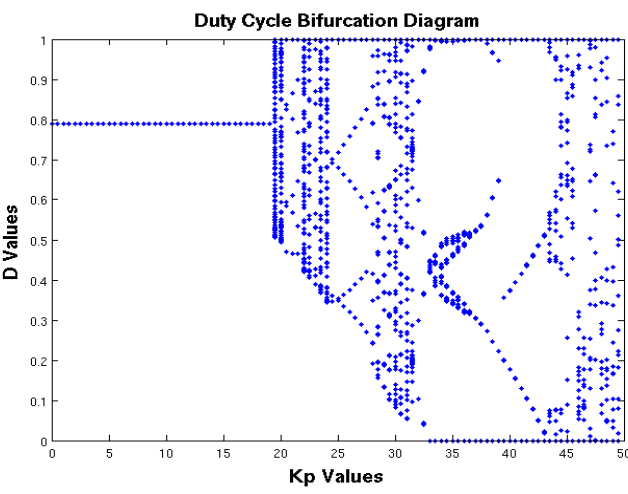

Figure 11. D's bifurcations

\section{2. $V_{C}$ and $D$ bifurcation diagrams with varying $T$}

Figure 12 shows that for small values of $T$ (sampling period), the system has a one periodic wave for high frequencies; however, by increasing the sampling period equal to the switching period (around $110 \mu \mathrm{seg}$ ), the systems begins to turn chaotic.

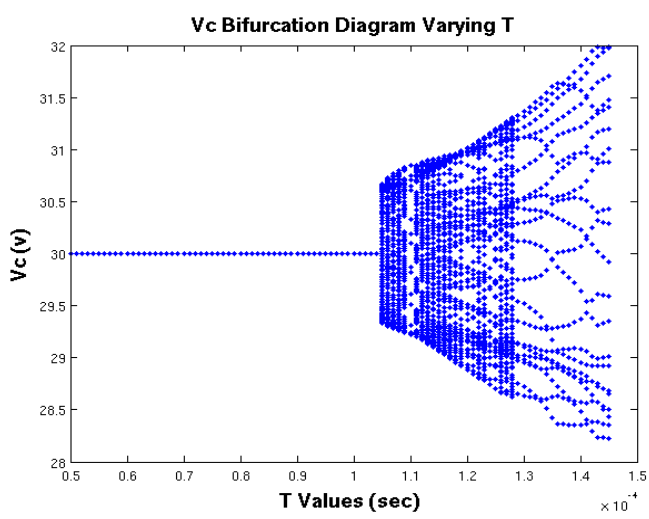

Figure 12. $V_{C}$ 's bifurcation diagram with varying $\mathrm{T}$

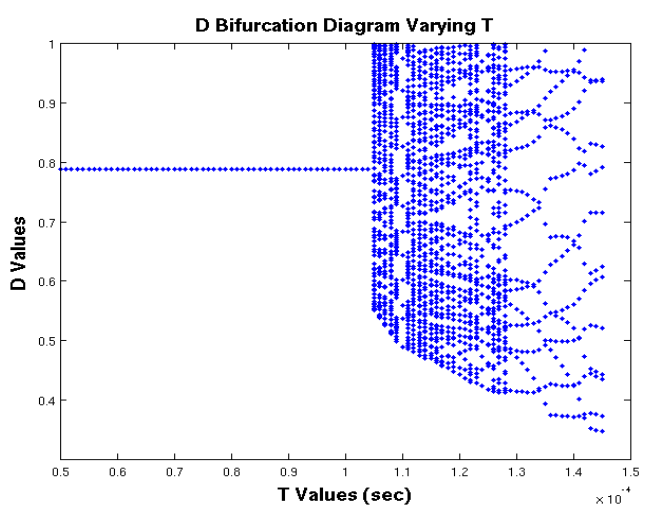

Figure 13. D’s bifurcation diagram with varying $T$

\section{MATLAB/SIMULINK® SIMULATION}

The next simulation performed in simulink moves us closer to real-time implementation performed in dSPACE. Figures 14 and 15, respectively, show the circuit diagrams and elements used. Figure 16 displays the output in open- and closed-loop systems with PID. Reducing the sampling rate to half causes the signal to lose symmetry because it receives fewer sampling points and, therefore, the integration process struggles as it adds more than needed or rests more than needed, for the same reason. This explains the strong oscillations seen in Figure 17. This effect is accentuated in the implementation. 


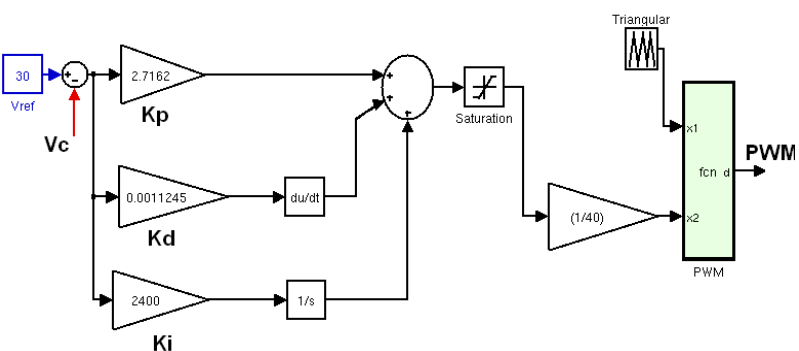

Figure 14. PID and PWM schema

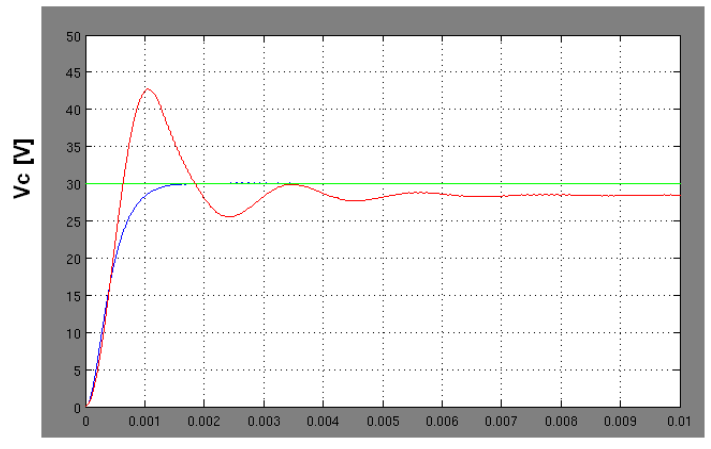

Figure 16. $V_{C}$ output in open- and closed-loop

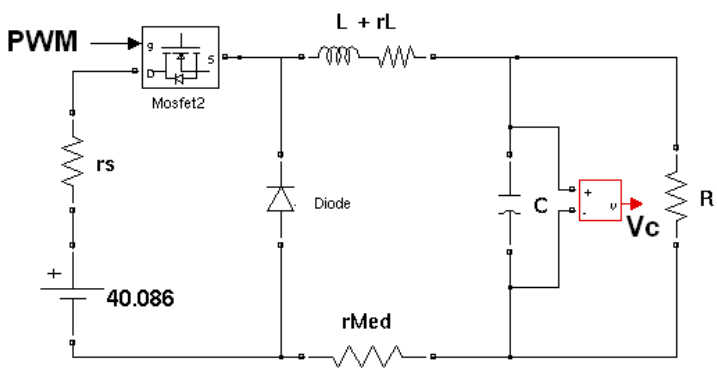

Figure 15. Buck converter

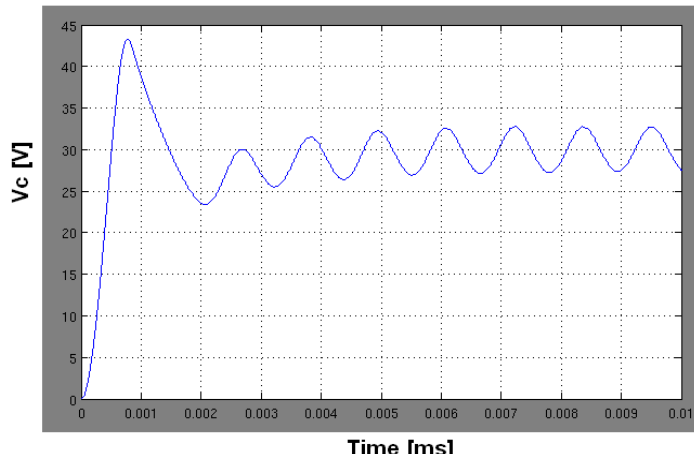

Figure 17. $V_{C}$ output with a minor sample frequency systems with PID

\section{EXPERIMENTAL RESULTS}

For real-time implementation, the control and development card dSPACE was used. The converter's PID controller was implemented in simulink as diagrammed in Figure 18, where it controls the controller implemented on hardware through the PWM generation block.

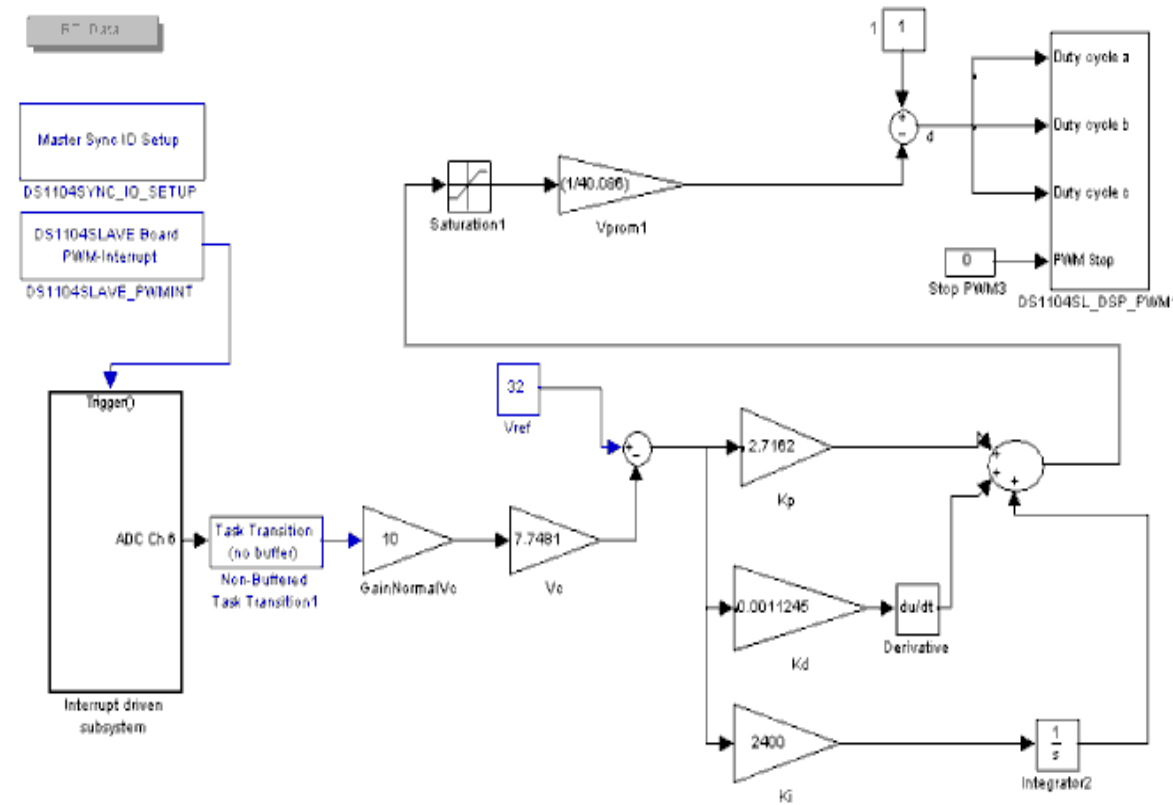

Figure 18: Rapid control prototyping to control the buck converter 
The results presented in this section were obtained with the experimental prototype and the parameters defined in Table 2. By changing the reference voltage to $10 \mathrm{~V}, 20 \mathrm{~V}$, and $30 \mathrm{~V}$, and varying the sampling and switching frequency, we show that the real system is much more sensitive to a low sampling rate. Figure 19 corresponds to a sampling frequency of $10 \mathrm{kHz}$. Increasing the sampling frequency three times $(30 \mathrm{kHz}) \mathrm{in}$ Figure 20 results in a little improvement in the regulated signal $V_{C}$ and, especially, a reduction in the sound produced by the inductor due to the switching frequency growth of the transistor.

By increasing significantly the value of the capacitor to $376 \mu \mathrm{F}$ as shown in Figure 21, we improve the converter's filtering and find a better answer with a lower steady-state error, even for the design parameters shown in Table 2. The reason is that more capacity filters higher frequencies and, therefore, the regulation is better, thus reducing considerably the system's chaos. It can be seen in Figures 22 and 23 that if we make instant load changes going from $14.59 \Omega$ to $39.3 \Omega$ with a capacitor of $376 \mu \mathrm{F}$ and switching to $10 \mathrm{kHz}$, then the system regulates too well with errors less than $2 \%$; hence, not only the good performance of the PID controller must be considered.

Table 2. Experimental Prototype Data

\begin{tabular}{lcc}
\hline & Parameter & Value \\
\hline$R:$ & Load resistance & $39.3 \Omega$ \\
$C:$ & Capacitance & 46.27 and $376 \mu F$ \\
$L:$ & Inductance & $2.473 \mathrm{mH}$ \\
$r_{i n t}:$ & Internal resistance of the source & $0.688 \Omega$ \\
$r_{L}:$ & Internal resistance of the inductor & $1.345 \Omega$ \\
$E:$ & Input voltage & $40.086 \mathrm{~V}$ \\
$F C:$ & Switching frequency & $10 \mathrm{kHz}$ and $30 \mathrm{kHz}$ \\
$F S:$ & Sampling frequency & $10 \mathrm{kHz}$ and $30 \mathrm{kHz}$ \\
$\mathrm{Kp}:$ & Proportional gain & 2.7162 \\
$\mathrm{Kd}:$ & Derivative gain & 0.0011245 \\
$\mathrm{Ki}:$ & Integral gain & 2400 \\
\hline
\end{tabular}

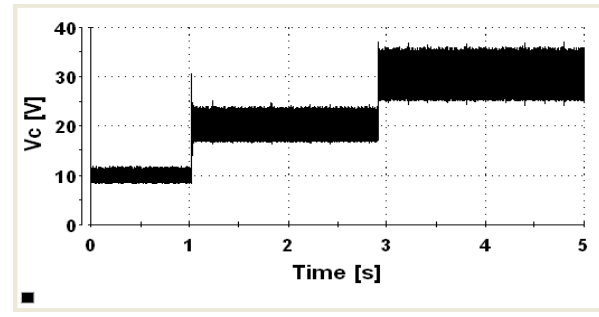

Figure 19. $V_{C}$ output with $C=46 \mu \mathrm{F}, V_{c}$ at $10 \mathrm{kHz}$

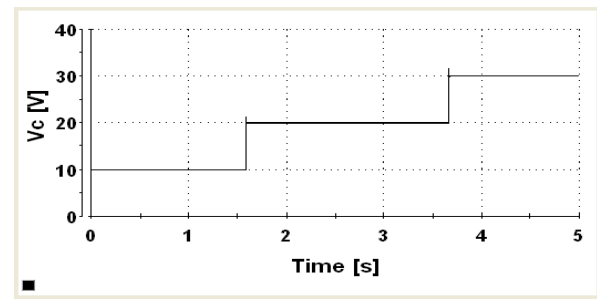

Figure 21. $V_{C}$ output with $C=376 \mu \mathrm{F}$ at $10 \mathrm{kHz}$

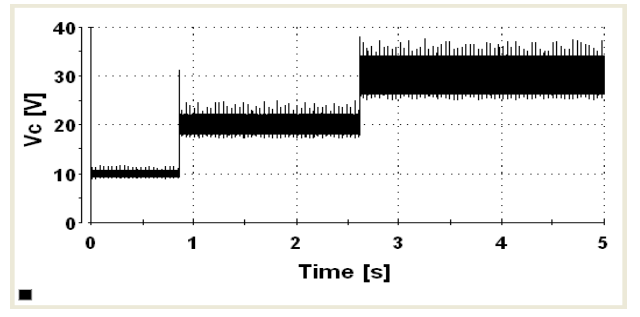

Figure 20. $V_{C}$ output with $C=46 \mu \mathrm{F}, V c$ at $30 \mathrm{kHz}$

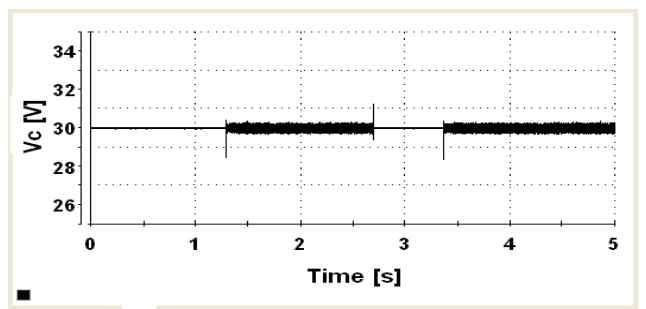

Figure 22. $V_{C}$ output with load changes $R$ with $C=376 \mu \mathrm{F}$

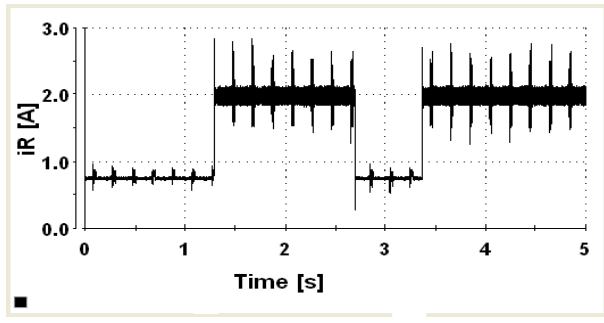

Figure 23. $I$ load $i_{R}$ with load changes $R$ with $C=376 \mu \mathrm{F}$ 


\section{CONCLUSIONS}

Because the increased value of the capacitor produced a substantial improvement in the system, it is necessary to propose a detailed study of the buck converters currently on the market in order to determine and compare which and what values of their elements are most appropriate to apply with different control techniques. It is likely that the implemented converter does not have the best features to adequately respond to PID control. The PID controller in the continuous case shows good performance in terms of regulating output voltage $\left(V_{C}\right)$. In some systems, a continuous PID control can react in a way and when is modulated by PWM change substantially; therefore, we should not assume that what is found in continuous time can be applied without restrictions in discrete time. The switching and sampling frequencies affect a major proportion of the integral because it needs to add the highest possible amount of points to successfully complete the integration process. Having hardware that supports high sampling and switching frequencies is a very important factor when implementing a system. For the implemented converter, the PID controller did not respond in the best way. It is necessary to filter or remove the derivative and select appropriate sampling and switching frequencies.

\section{ACKNOWLEDGMENTS}

This work was supported by the Universidad Nacional de Colombia, Sede Medellín under the projects HERMES-34671 and HERMES-36911. The authors thank the School of Physics for their valuable support to conduct this research. This research paper corresponds to "programa reconstrucción del tejido social en zonas de pos-conflicto en Colombia del proyecto Modelo ecosistémico de mejoramiento rural y construcción de paz: instalación de capacidades locales," financed by the "Fondo Nacional de Financiamiento para la Ciencia, la Tecnología y la Innovación, Fondo Francisco José de Caldas con contrato No 213-2018 con Código 58960.”

\section{REFERENCES}

[1] Yousefzadeh V. Haitao Hu. and Maksimovic D., "Nonuniform A/D quantization for improved dynamic responses of digitally controlled DC-DC converters," Power Electronics, IEEE Transactions on, Vol. 23 , no. 4, pp. 1998 - 2005, 2008.

[2] DeGusseme K. VandeSype D.M., VandenBossche A.P. DeBelie F.M.L.L., and Melkebeek J.A. "Small-signal zdomain analysis of digitally controlled converters," Power Electronics, IEEE Transactions on Vol. 21 , no. 2, pp. 470 - 478, 2006.

[3] Maksimovic D. and Zane R., "Small-signal discrete-time modeling of digitally controlled DC-DC converters," Computers in Power Electronics, 2006. COMPEL '06. IEEE Workshops on, pp. 231 - 235, 2006.

[4] Zane R. Maksimovic D. and Erickson R. "Impact of digital control in power electronics," Power Semiconductor Devices and ICs, 2004. Proceedings. ISPSD '04. The 16th International Symposium on, pp. 13 - 22, 2004.

[5] Maksimovic D. Prodic A. and Erickson R.W., "Digital controller chip set for isolated dc power supplies," Applied Power Electronics Conference and Exposition, 2003. APEC '03. Eighteenth Annual IEEE Vol. 2, pp. 866 - 872, 2003.

[6] Peterchev A.V. and Sanders S.R., "Quantization resolution and limit cycling in digitally controlled pwm converters," Power Electronics, IEEE Transactions on, Vol. 18 , no. 1, Part: 2, pp. 301 - 308, 2003.

[7] M. Habbab, A. Hazzab, and P. Sicard., "Real Time Implementation of Fuzzy Adaptive PI-sliding Mode Controller for Induction Machine Control," International Journal of Electrical and Computer Engineering (IJECE), Vol. 8, No. 5, pp. 2884-2894, October 2018.

[8] E. Rakhman, Feriyonika., "Distributed Control System Applied in Temperatur Control by Coordinating Multi-loop Controller," Telecommunication Computing Electronics and Control (TELKOMNIKA), Vol. 16, No. 4, pp. 1568-1576, August 2018.

[9] A. Prayitno, V. Indrawati, I. I. Trusulaw, "Fuzzy Gain Scheduling PID Control for Position of the AR.Drone," International Journal of Electrical and Computer Engineering (IJECE). Vol. 8, No. 4, pp. 1939-1946, August 2018.

[10] F. E. Hoyos, J. E. Candelo, and J. A. Taborda, "Selection and Validation of Mathematical Models of Power Converters using Rapid Modeling and Control Prototyping Methods," International Journal of Electrical and Computer Engineering (IJECE), Vol. 8, No. 3, pp. 1551-1568, June 2018.

[11] Prodic A. Hao P, Maksimovic D. and Alarcon E., "Modeling of quantization effects in digitally controlled DC-DC converters," Power Electronics, IEEE Transactions on, Vol. 18 , No. 1, Part. 2, pp. 301 - 308, 2003.

[12] Liu C.P. Fung C.W. and Pong M.H. "A diagrammatic approach to search for minimum sampling frequency and quantization resolution for digital control of power converters," Power Electronics Specialists Conference, 2007. IEEE, pp. 826 - 832, 2007.

[13] Gregory Chong. Kiam Heong Ang. and Yun Li., "PID control system analysis, design, and technology," IEEE Transactions on control systems technology, Vol. 13, No. 4, July 2005.

[14] E. Fossas and G. Olivar, "Study of chaos in the buck converter," IEEE transactions on Circuits and Systems-I: Fundamental Theory and Applications, 43, 13-25, 1996. 
[15] D.C Hamill, J.H.B. Deane, and D.J Jefferies, "Modeling of chaotic dc-dc converters by iterated nonlinear mappings," IEEE transactions on Power Electronics, 7:25-36, 1992.

[16] D. Hart, "Electrónica de Potencia," Prentice Hall, Madrid, España, 2001.

[17] N. Mohan, T. Undeland, and W. Robbins, "Power Electronics: Converters. Aplications and Design,” J. Wiley, 1995.

[18] G. Olivar, "Chaos in the Buck Converter," PhD thesis. Universidad Politécnica de Cataluña. Spain, Available at: http://www.tdx.cat/handle/10803/5841, 1997.

\section{BIOGRAPHIES OF AUTHORS}
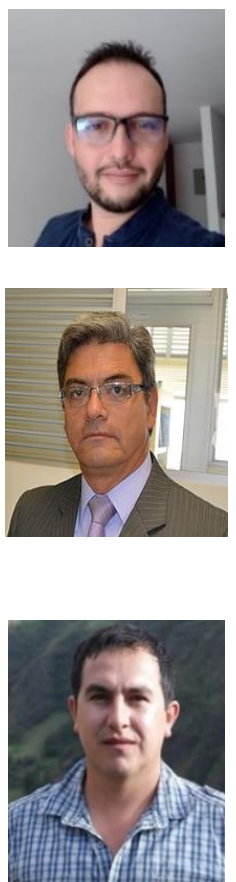

Odair A. Trujillo: received a B.S. in electrical engineering and M.S. in automatics from Universidad Nacional de Colombia, Manizales in 2008 and 2013, respectively. His research interests include nonlinear control, nonlinear dynamics of nonsmooth systems, and power electronic converters. He is a member of the reasearch group in power resources GIRE.

Nicolás Toro: received a B.S. in electrical engineering and Ph.D. in automatics from Universidad Nacional de Colombia, Manizales in 1983 and 2012, respectively, as well as an M.S. in production automatic systems from Universidad Tecnológica de Pereira, Colombia in 2000. He is currently an Associate Professor in the Department of Electrical Engineering, Electronics, and Computer Science, Universidad Nacional de Colombia, Sede de Manizales. His research interests include nonlinear control, nonlinear dynamics of nonsmooth systems, and power electronic converters. He is a member of the reasearch group in power resources GIRE (Código colombiano de registro: COL0144229), at Universidad Nacional de Colombia. https://orcid.org/0000-0001-8317-4126

Fredy E. Hoyos: electrical engineer, MEng Industrial Automation, Ph.D in Automation; Assistant Professor, Science Faculty, School of Physics, Universidad Nacional de Colombia Sede Medellín, Colombia; E-mail: fehoyosve@ unal.edu.co. His research interests include nonlinear control, nonlinear dynamics of nonsmooth systems, and power electronic applications. He is an Associate Researcher in Colciencias and a member of the reasearch group in Digital Signal Processing for Real-Time Systems at Universidad Nacional de Colombia. https://orcid.org/0000-0001-8766-5192 